\title{
Immunization of Persons with HIV Infection and other Secondary Immunodeficiencies
}

\author{
LRR Castello-Branco ${ }^{+}$, MB Ortigão-de-Sampaio
}

\begin{abstract}
Laboratório de Imunologia Clínica, Departamento de Imunologia, Instituto Oswaldo Cruz, Av. Brasil 4365, 21045-900 Rio de Janeiro, RJ, Brasil
\end{abstract}

Patients with secondary immunodeficiencies are at a high risk of infection. Currently some of these infections are preventable through specific immunization. Prevention of these diseases can diminish morbidity and mortality amongst these patients. In this review we describe the use of vaccines in persons with secondary immunodeficiencies.

Key words: immunization - vaccines - HIV infection - secondary immunodeficiencies

The number of patients with secondary immunodeficiencies has increased rapidly in the last three decades. This is secondary to the improvement in cancer treatment, the use of immunosupressive drugs in autoimmune diseases and transplants, and mainly due to HIV infection (CDC 1991, Ljungman 1995).

Immunocompromised patients are at a high risk of infection and some of these are preventable through specific immunization. Prevention of these diseases can diminish morbidity and mortality amongst these patients. Therefore, a full understanding of their disease, knowledge when to immunize them and the right use of these vaccines are mandatory to any physician following such patients.

In this review we describe the use of vaccines in persons with secondary immunodeficiencies.

\section{VACCINES}

Usually immunization is indicated to protect individuals or populations against serious infections, diminish the number of infected people and, as the main goal, eradicate the disease.

The World Health Organization (WHO) has recommended some vaccines that are used worldwide and some governments adopt other vaccines depending on the prevalence of such diseases in their countries (Table).

Vaccines can be divided into two groups (Table): killed, inactivated or subunit and live vaccines (WHO/EPI 1995).

${ }^{+}$Corresponding author. Fax: +55-21-280.1589. E-mail: branco@gene.dbbm.fiocruz.br

Received 11 March 1998

Accepted 16 April 1998
TABLE

Vaccines used worldwide

\begin{tabular}{|c|c|}
\hline Live vaccines & $\begin{array}{l}\text { Killed, inactivated and } \\
\text { subunit vaccines }\end{array}$ \\
\hline $\begin{array}{l}\text { BCG }^{a} \\
\text { Measles }^{b} \\
\text { Mumps } \\
\text { Oral poliomyelitis (Sabin) } \\
\text { Rubella } \\
\text { Yellow fever }\end{array}$ & $\begin{array}{l}\text { Cholera } \\
\text { Diphteria }^{b} \\
\text { Haemophilus influenza } \\
\text { Hepatitis A } \\
\text { Hepatitis B }{ }^{b} \\
\text { Inactivated polio (Salk) }{ }^{b} \\
\text { Influenza } \\
\text { Japanese B encephalitis } \\
\text { Meningococcus } \\
\text { Pertussis } b \\
\text { Pig Bel } \\
\text { Pneumococcus } \\
\text { Rabies } \\
\text { Tetanus } b \\
\text { Typhoid }\end{array}$ \\
\hline
\end{tabular}

$a$ : recommended in endemic countries (EPI - WHO); $b$ : vaccines used in the EPI (WHO).

\section{TYPES OF ACQUIRED IMMUNOSUPRESSION}

Secondary immunodeficiencies can be divided into three different groups: (1) Non HIV severe immunodeficiency; (2) Common variable immunodeficiency (limited immune deficits) and (3) HIV infection.

\section{NON HIV SEVERE SECONDARY IMMUNODEFI- CIENCY}

Non HIV severe secondary immunodeficiency can be due to a variety of conditions such as leukaemia, lymphoma, generalized malignancy or therapy with alkylating agents, antimetabolites, radiation, or large amounts of corticosteroids (CDC 1993).

Killed or inactivated vaccines do not represent a danger to immunocompromised persons and should be administered as recommended for 
healthy persons. In, contrast live-virus vaccines and live-bacteria vaccines such as Mycobacterium bovis $\mathrm{BCG}$ are contraindicated for persons that are severely immunocompromised. Oral polio vaccine is contraindicated to any person that is in contact (health care providers and household contacts) with a severely immunodepressed patient (CDC 1993, WHO EPI 1995).

Administration of live-virus vaccine in patients on treatment with steroids is not contraindicated when steroid therapy is: (1) short term (less than two weeks); (2) low to moderate dose; (3) longterm alternate day treatment with short acting preparations; (4) replacement therapy; (5) administered topically. A dose equivalent to either $2 \mathrm{mg} /$ $\mathrm{kg}$ of body weight or a total of $20 \mathrm{mg} /$ day of prednisone is sufficiently immunossupressive to raise concern about safety of immunization with livevirus vaccines (CDC 1993).

\section{COMMON VARIABLE IMMUNODEFICIENCY}

Common variable immunodeficiency is secondary to diseases that cause limited deficits and may require use of special vaccines or higher doses of vaccines but that do not contraindicate use of any particular vaccine. Some of these immunocompromised patients lose protective immunity to infections such as tetanus, poliovirus (Ljungman et al. 1990, 1991) and others become susceptible to infections such as haemophilus and pneumococcus (Ljungman 1995). Patients with limited immunocompromising conditions (e.g., asplenia, diabetes, alcoholic cirrhosis) may be at higher risk for certain diseases, and additional vaccines, particularly bacterial polysaccharide vaccines (Haemophilus influenza type b- Hib, pneumococcal and meningococcal), are recommended for them. Hepatitis B is indicated for patients with renal failure. Higher doses or more frequent boosters of these vaccines may be required as the immune response of these immunocompromised subjects may be suboptimal.

\section{HIV INFECTION}

HIV-infected subjects are likely to present a more severe outcome of infections targeted by immunizations than seronegative individuals. For example, measles tends to occur earlier in life (Embree et al. 1992) and has a high mortality rate in HIV-infected children as compared to seronegative ones (Kaplan et al. 1992). Other diseases like tuberculosis, whose incidence has increased dramatically worldwide due to the HIV epidemic, is more likely to be associated with progressive AIDS than in seronegative persons (Schulzer et al. 1992). The antimycobacterial therapy is less effective and the mortality rate is higher in these in- dividuals (Nunn 1990). The severity of these illnesses is the basis for the recommendation of basic immunization in HIV-infected individuals.

A major concern regards the effectiveness of vaccines in seropositive persons and their ability to respond to immunogens. Indeed, HIV-infected children are capable of mounting cellular and humoral immune responses to common vaccines in the first two years of life, but these responses decline during the following years and the seroconversion rates decrease with progression to AIDS (Borkowsky et al. 1992). The antibody levels tend to be lower and to decrease more rapidly over time in HIV-infected individuals than in non-infected persons (Ryder et al. 1993). The suboptimal antibody responses occur particularly after immunization with CD4-lymphocyte-dependent antigens such as the polysaccharide-based pneumococcal and $H$. influenzae vaccines (Ljungman 1995).

Another major concern is the safety of immunization, particularly with live-attenuated vaccines. Since HIV infection results in progressive deterioration of the immune system, the use of live immunogens could cause severe vaccine-associated diseases. Prospective studies comparing BCG immunization in HIV-infected and non infected children have failed to show any difference in the risk of regional complications (Ryder et al. 1993). However, there have been isolated reports of disseminated BCG disease in HIV-infected adults and children (Blanche et al. 1986, Houde \& Dery 1988, Smith et al. 1992). In HIV-infected adults, disseminated BCG disease can be a late complication and has been reported 30 years after immunization (Reynes et al. 1989). Studies of measles, mumps and rubella and oral polio vaccination among asymptomatic and symptomatic HIV-infected subjects have not documented serious or unusual adverse effects. However, administration of oral polio vaccine to children with congenital immunodeficiencies, particularly agammaglobulinemia, has resulted in severe progressive neurologic disorders (Davies et al. 1977).

Another important aspect to be considered in the immunization of HIV-infected individuals is the enhancement of viral replication following immune stimulation. The stimulation of CD4 lymphocytes is an important factor for HIV replication (Fauci 1996). It has been demonstrated in vitro that cell-cell interaction during antigen presentation, through the engagement of adhesion molecules LFA-1 and ICAM-1, is a potent inducer of HIV transcription (Shattock et al. 1996). In vivo increased plasma viral load has been reported following parenteral (Staprans et al. 1995, Stanley et al. 1996) as well as oral (Ortigão-de-Sampaio et 
al. 1997) immunization. However, the increase in viral load in these reports was transient, returning to base levels 15 to 21 days post-immunization, and without any clinical adverse reactions.

Currently, WHO/UNICEF recommends that the immunization schedule for HIV-infected individuals should follow the national standards for each country. All live vaccines should be avoided, particularly in adults. Nevertheless, BCG vaccine is recommended for asymptomatic HIV-infected children living in high risk conditions of tuberculosis. Due to the risk of early and severe measles infection, these infants should receive two doses of measles vaccine at six and nine months of age. Although oral live-attenuated polio vaccine has not been harmful when administered to asymptomatic HIV-infected children, killed virus vaccine should be preferred when available. Pneumococcal vaccine should be given to all HIV-infected persons with two or more years of age. Children older than two years should receive Hib vaccine according to routine schedule. Other vaccines such as hepatitis B are recommended to HIV adults and children, although more studies concerning its effectiveness are still to be done.

In conclusion the use of the right vaccines in immunocompromised subjects is fundamental to increase the quality of life of these patients and the prevention of such infectious diseases is less expensive for governments than the not always well succeeded treatment of these life threatening infections.

\section{REFERENCES}

Blanche S, LeDeist F, Fischer A, Veber F, Debre M, Chamaret S, Montagnier L, Griscelli C 1986. Longitudinal study of 18 children with perinatal LAV/ HTLVIII infection: attempt at prognostic evaluation. J Pediatr 109: 965-970.

Borkowsky W, Rigaud M, Krasinski K, Moore T, Lawrence R, Pollack H 1992. Cell-mediated and humoral immune responses in children infected with human immunodeficiency virus during the first four years of life. J Pediatr 120: 371-375.

CDC 1991. Update on adult immunization: recommendations of the Advisory Committee on Immunization Practices (ACIP). MMWR 41(N. RR-12).

CDC 1993. Recommendations of the Advisory Committee on Immunization Practices (ACIP). Use of vaccines and immune globulins in persons with altered immunocompetence. $M M W R$ 42(N. RR-4).

Davies LE, Bodian D, Price D, Butler IJ, Vickers JH 1977. Chronic progressive poliomyelitis secondary to vaccination in immunodeficient child. $N$ Engl $J$ Med 297: 241-245.

Embree JE, Datta P, Stackiw W, Sekla L, Braddick M, Kreiss JK, Pamba H, Wamola I, Ndinya-Achola JO, Law BJ et al. 1992. Increased risk of early measles in infants of human immunodeficiency virus type 1seropositive mothers. J Infect Dis 165: 262-267.

Fauci A 1996. Host factors and the pathogenesis of HIVinduced disease. Nature 384: 529-534.

Houde C, Dery P 1988. Mycobacterium bovis sepsis in an infant with human immunodeficiency virus infection. Pediatr Infect Dis J 7: 810-812.

Kaplan LJ, Daum RS, Smaron M, McCarthy CA 1992. Severe measles in immunocompromised patients. JAMA 267: 1237-1241.

Ljungman P 1995. Immunization in the immunocompromised host. Curr Op Infect Dis 8: 254-257.

Ljungman P, Duraj V, Magnius L 1991. Response to immunization against polio after allogeneic marrow transplantation. Bone Marrow Transplant 7: 89-93.

Ljungman P, Wiklund-Hammarsten M, Duraj V, Hammarstrom L, Lonnqvist B, Paulin T, Ringden O, Pepe MS, Gahrton G 1990. Response to tetanus toxoid immunization after allogeneic bone marrow transplantation. J Infect Dis 162: 496-500.

Nunn P 1990. Impact of human immunodeficiency virus on transmission and severity of tuberculosis. Trans R Soc Trop Med Hyg 88 (Suppl 1): 9.

Ortigão-de-Sampaio MB, Shattock RJ, Hayes P, Griffin GE, Linhares-de-Carvalho MI, Lewis DJM, Castello-Branco LRR 1997. HIV Replication and Immune Response in Brazilian Male Homosexuals Following Mucosal Immunization with Oral Cholera Vaccine, p. 122. Symposium on HIV-1 Infection, Mucosal Immunity and Pathogenesis, Bethesda, USA.

Reynes RW, Perez C, Lamaury I, Janbom F, Bertrand A 1989. Bacille Calmette-Guerin adenitis 30 years after immunization in a patient with AIDS. $J$ Infect Dis 160: 727.

Ryder RW, Oxtoby MJ, Mvula M, Batter V, Baende E, Nsa W, Davachi F, Hassig S, Onorato I, Deforest A et al. 1993. Safety and immunogenicity of bacille Calmette-Guerin, diphtheria-tetanus-pertussis, and oral polio vaccines in newborn children in Zaire infected with human immunodeficiency virus type 1 . J Pediatr 122: 697-702.

Schulzer M, Fitzgerald JM, Enarson DA, Grzybowski S 1992. An estimate of the future size of the tuberculosis problem in sub-Saharan Africa resulting from HIV infection. Tubercle Lung Dis 73: 52-58.

Shattock RJ, Rizzardi GP, Hayes P, Griffin GE 1996. Engagement of adhesion molecules (CD18, CD11a, CD45, CD44, and CD58) enhances human immunodeficiency virus type-1 replication in monocytic cells through a tumor necrosis factor-modulated pathway. J Infect Dis 174: 54-62.

Smith E, Thybo S, Bennesden J 1992. Infection with Mycobacterium bovis in a patient with AIDS: a late complication of BCG vaccination. Scand J Infect Dis 24: 109-110.

Stanley SK, Ostrowski MA, Justement JS, Gantt K, Hedayati S, Mannix M, Roche K, Schwartzentruber DJ, Fox CH, Fauci AS 1996. Effect of immunization with a common recall antigen on viral expression in patients infected with human immunodeficiency virus type 1. N Engl J Med 334: 1222-1230. 
Staprans SI, Hamilton BL, Follansbee SE, Elbeik T, Barbosa P, Grant RM, Feinberg MB 1995. Activation of virus replication after vaccination of HIV-1infected individuals. J Exp Med 182: 1727-1737.
WHO/EPI-World Health Organization/Expanded Programme on Immunization 1995. Global Programme for Vaccines and Immunization: Immunization Policy. Document WHO/EPI. 